Document downloaded from:

http://hdl.handle.net/10251/163184

This paper must be cited as:

Buitrago, M.; Calderón García, PA.; Moragues, JJ.; Alvarado, YA.; Adam, JM. (2021). Load limiters on temporary shoring structures: Tests on a full-scale building structure under construction. Journal of Structural Engineering. 147(3):1-9.

https://doi.org/10.1061/(ASCE)ST.1943-541X.0002948

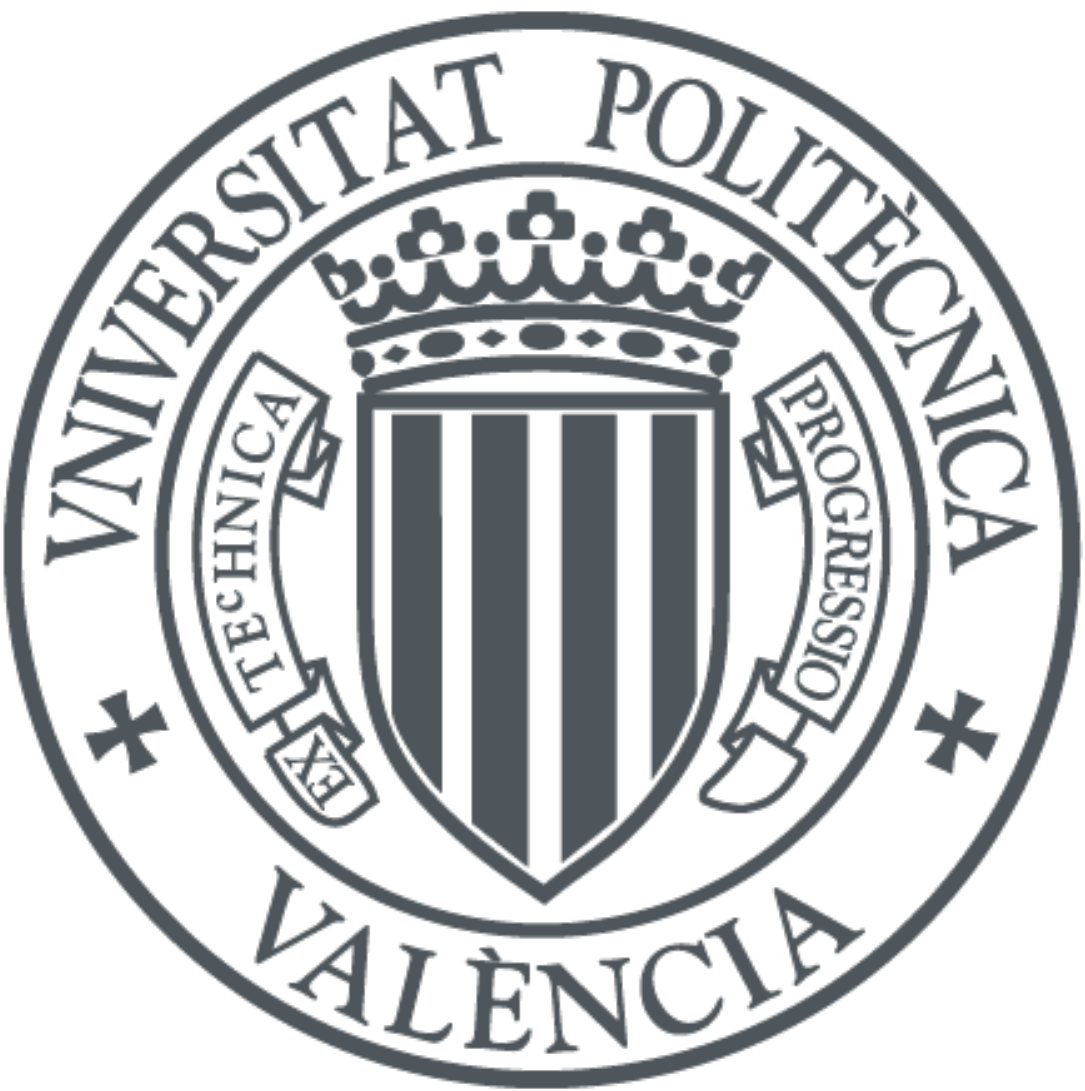

The final publication is available at

https://doi.org/10.1061/(ASCE)ST.1943-541X.0002948

Copyright American Society of Civil Engineers

Additional Information 


\title{
Load limiters on temporary shoring structures: Tests on a full-scale building structure under construction
}

\author{
Manuel Buitrago, Ph.D. ${ }^{1 *}$; Pedro A. Calderón, Ph.D. ${ }^{2}$ Juan J. Moragues, Ph.D. ${ }^{3}$; Yezid A. Alvarado, Ph.D.4; José \\ M. Adam, Ph.D. ${ }^{5}$ \\ ${ }^{1}$ Senior Researcher, ICITECH, Universitat Politècnica de València. Camino de Vera s/n, 46022 Valencia, Spain. ORCID: \\ https://orcid.org/0000-0002-5561-5104.Email: mabuimo1@upv.es \\ ${ }^{2}$ Full Professor, ICITECH, Universitat Politècnica de València. Camino de Vera s/n, 46022 Valencia, Spain. ORCID: \\ https://orcid.org/0000-0002-9783-9333 \\ ${ }^{3}$ Full Professor, ICITECH, Universitat Politècnica de València. Camino de Vera s/n, 46022 Valencia, Spain. \\ ${ }^{4}$ Associate Professor, Pontificia Universidad Javeriana. Calle 40 No. 5-50 Ed. José Gabriel Maldonado, S.J., Bogotá, Colombia, ORCID: \\ https://orcid.org/0000-0002-1260-8211 \\ ${ }^{5}$ Full Professor, ICITECH, Universitat Politècnica de València. Camino de Vera s/n, 46022 Valencia, Spain, ORCID: \\ https://orcid.org/0000-0002-9205-8458 \\ * Corresponding author. Tel.: +34 963877562; fax: +34 963877568. \\ E-mail address: mabuimo1@upv.es (Manuel Buitrago).
}

\section{Abstract}

Temporary shoring structures are used in the construction of reinforced concrete buildings to transmit the loads of newly poured slabs onto the lower floors. The main problems involved in the use of shores/props are: a) the possibility of having higher loads than those initially foreseen, and b) the

21 structural efficiency and cost of the system, which is normally over-sized due to being designed to bear 22 the maximum load of the most demanding building operation. This paper describes a test carried out on 23 a full-scale one-story building to analyze the behaviour of load limiters (LLs) installed on shores under 24 actual construction loading conditions. The theoretical approach and development of this new LL 25 concept were described in previous papers. As these LLs still had not been tested in actual buildings, 26 this paper covers the existing need for a test in the form of a "proof of concept". It also includes 27 computer simulations and recommendations for the use of LLs.

28 Keywords: Building structures, Construction, Load limiters, Real-scale test, Shores, Structural fuses, 


\section{Introduction}

31 Temporary shoring structures are normally used when building different structures (e.g. bridges and 32 buildings) to support them during building operations until they have attained sufficient strength to 33 support the loads they have to bear (self-weight and early-age construction loads). The most frequently 34 used method in reinforced concrete structures is the shoring of successively shored floors (Adam et al. 35 2017), in which shores (or props) are designed to bear the maximum load of the most demanding 36 building operation on any part of the structure (Buitrago et al. 2016a).

37 All the shores used during construction are generally designed to bear the maximum load. If there is a 38 big difference between the maximum and minimum loads borne by the shores due to the type of 39 structure, the actions or the building process itself, this can lead to an inefficient and excessively costly 40 shoring system, so that reducing the difference will allow more efficient and economic temporary 41 systems (Buitrago et al. 2015, 2016b).

42 Theoretical models can be used to calculate the theoretical load distribution on the shores of a floor at 43 every operation during the building process. However, for a number of reasons associated with the 44 shores (e.g. their fixing system controlled by a workman, different axial stiffness, secondary bending 45 moments, deviations from the vertical position, the manufactured lot, or accumulated damage) can make 46 the theoretical deviate from the actual distribution, or even make the maximum load experienced be 47 greater than that calculated. In fact, many authors have analyzed this phenomenon of the load 48 distribution on shores after slab pouring (Karshenas and Ayoub 1994; Liu et al. 1985; Zhang et al. 2016) 49 or during the entire construction process (Alvarado et al. 2009; Calderón et al. 2011; Fang et al. 2001; $50 \quad$ Gasch et al. 2015).

51 All this uncertainty, increased by possible human errors (e.g. unexpected overloads, early striking or 52 substandard materials and workmanship) or structural design (e.g. anchorage lengths of rebars, 53 insufficient punching shear reinforcement or absence of reinforcement) increase the potential failure rate 
54 during construction (Buitrago et al. 2018b; Carper 1987; Ellingwood 1987; Epaarachchi et al. 2002;

55 Hadipriono 1985; Hadipriono and Wang 1987; Schellhammer et al. 2013) or in the serviceability stage 56 (Adam et al. 2017; Alvarado et al. 2017; Ghali and Gayed 2014).

57 In this context the idea of using load limiters (LLs) on shores was conceived to improve structural safety 58 and avoid failures during building construction. Their advantages also include improving the shoring 59 system's structural efficiency and reducing its costs. This new concept has been widely studied in 60 previous work (see Section 2 for further information). This paper's novelty lies in the fact that it 61 involves tests on a full-scale one-floor one-bay building under construction in which the shores were 62 fitted with LLs and monitored during the entire process. The results obtained, in conjunction with the 63 associated computer simulations, provide ample proof of the LL concept under actual working 64 conditions.

65 After this Introduction, Section 2 describes the background to the project, Section 3 describes the LLs 66 themselves and the tests carried out. Sections 4 and 5 contain both the test and the computer simulation 67 results, plus a number of practical recommendations. Conclusions are given in Section 6.

\section{2. Background}

69 The LL concept was born due to the need to improve structural safety and the efficiency of temporary 70 shoring structures during building construction, with the secondary goal of reducing costs (Buitrago et 71 al. 2015). This new device is fitted to shores to restrict their loads to a set design limit, which is always 72 lower than their allowable load. The aim is therefore to avoid individual shores from being forced out of 73 service and to keep them all operational under normal and accidental construction situations (Buitrago et 74 al. 2015, 2018c; a, 2020). Shores with LLs should be characterized by elastic plastic behaviour, with the 75 first stiff elastic linear behavior, which changes to plastic on reaching the design limit load. 
76 If the shore-LL unit enters the plastic phase on reaching the set load, the higher loads produced by the

77 successive building stages will be diverted to the neighboring shores, while the shore will experience

78 vertical deformation that should be compatible with the general behavior of the structure.

79 The technical viability of this solution and its financial repercussions have been demonstrated in 80 Buitrago et al (2015), which concluded that LLs improved the structural safety of buildings during 81 construction and the efficiency of the temporary shoring structure in terms of costs and the use of the 82 shores' load-bearing capacity.

83 A prototype of LL was then designed, produced (Buitrago et al. 2018a), patented (ES2636833 84 Calderón et al. 2017) and was considered as an example of the new LL concept. It successfully 85 overcame the many experimental tests to which it was subjected, including those in which it was 86 installed on shoring systems (Buitrago et al. 2018a) and demonstrated its capacity for re-use. However, 87 it still had not been tested in a temporary shoring structure in a building under construction. Fig. 1 shows 88 an example of an LL. Further information on its design and operation can be found in Buitrago et al. 89 (2018a).

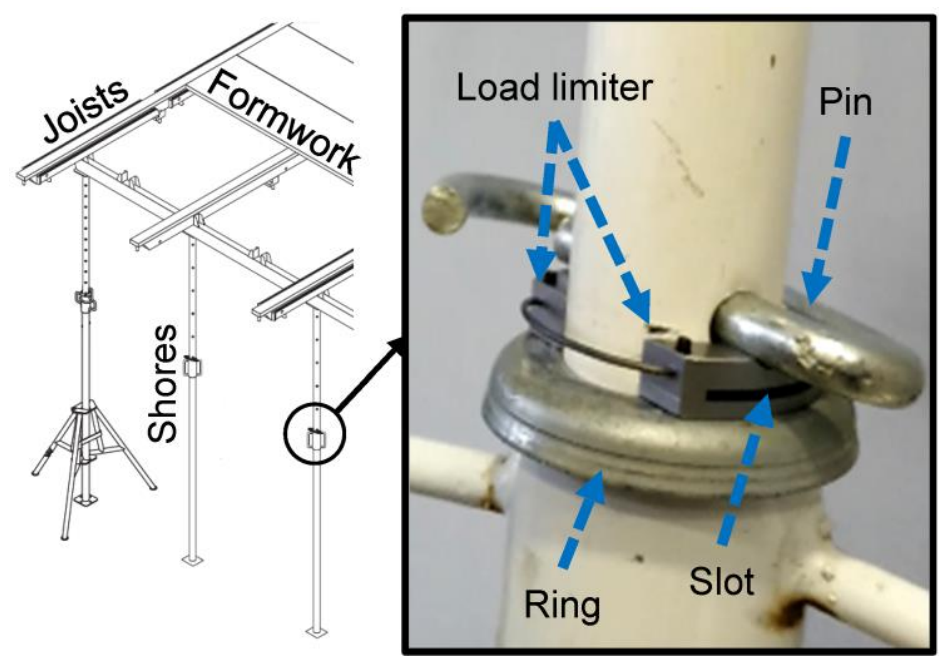

Fig. 1. Shore equipped with an $L L$.

92 Studies were also made of LLs' advantages for improving the robustness of permanent and temporary 93 structures during construction, a vitally important aspect, since any local failure in these can cause a 
94 chain reaction throughout the entire structure (Buitrago et al. 2018c). Structural robustness during the 95 serviceability stage and against extreme events is now an intensely studied field, e.g. RC building 96 structures during the serviceability stage (Adam et al. 2018; El-Tawil et al. 2014; Qian and Li 2013; 97 Sasani et al. 2011; Sasani and Sagiroglu 2008). However, on this subject, structures during the building 98 phase have not so far been completely studied or considered, in spite of the fact that some building 99 codes, such as the British (BS 5975 2011) do deal with the subject. Buitrago et al. (2018c) showed that 100 using LLs on shores acting as structural fuses can improve the robustness of temporary shoring and 101 reduce the risk of progressive collapse.

102 The study described here covers the existing need to experimentally validate the use of LLs on shores, 103 since they had never been actually used in the construction of a real building. For this final validation, 104 LLs were fitted to shores in a full-scale 3D test (Sections 3-4-5) and accompanied by a complementary 105 numerical simulation (Section 5).

\section{3. Description of the test}

\section{3.1. Design}

108 The tests were carried out in a full-scale, one-floor, $5.25 \times 5.25 \mathrm{~m}^{2}$ building with a reinforced concrete slab 109 and four steel columns at each corner. This configuration ensured a two-way bending behaviour of the 110 slab to analyze the load redistribution when LLs were activated. The floor-to-ceiling height was $2.40 \mathrm{~m}$.

111 Fig. 2 shows one of the shored floors and a photo taken before concrete pouring.
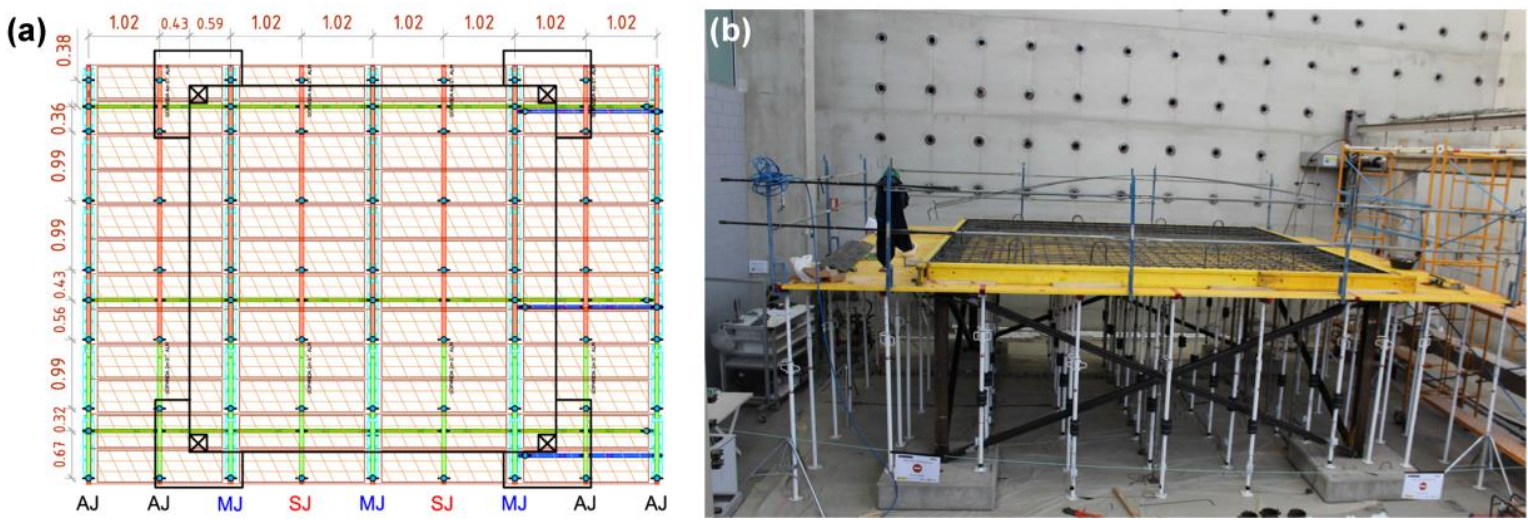

Fig. 2. Plan view of the shoring system (a) and photo of the building structure before concrete pouring (b). 
114 The four steel columns were at $5.00 \mathrm{~m}$ from each other and connected to RC footings, which in turn were 115 supported by the ICITECH laboratory foundations. Four Saint Andrew's crosses were connected to the 116 four columns to keep them vertically and horizontally stable. The design compressive characteristic 117 strength of the concrete was 30MPa and the nominal yield strength of the steel reinforcement bars was 118 500MPa. Concrete compressive strength and its evolution were measured during the construction of the 119 building (see Section 3.4). Slab thickness was $20 \mathrm{~cm}$ with reinforcement arranged in two layers and two 120 directions (16mm and $8 \mathrm{~mm}$ bar diameter in the lower and upper layer, respectively; separation $20 \mathrm{~cm})$.

121 Test measurements were carried out in real time and the shore loads were monitored during the building 122 construction. The formwork consisted of different elements: shores, joists and formwork boards. Fig. 2 123 shows the arrangement, with MJ representing the main joists kept operational until the final striking, SJ 124 representing the secondary joists kept operation until the partial striking, and AJ the joists used for 125 auxiliary material up to the partial striking (see Section 3.4 for further details).

\section{3.2. LLs and preliminary tests}

127 Before starting work on the building, the new LLs were designed, produced and tested. Computational 128 models (Buitrago et al. 2018a) were used to design LLs with a design limit load of 16.0kN. The 129 calculated maximum load without LLs was $23.0 \mathrm{kN}$ and the LLs were expected to come into action at 130 considerably less than the maximum load.

131 Two LLs (P1 and P2) were tested individually following the procedure laid down in a previous study 132 (Buitrago et al. 2018a). Fig. 3 shows the results obtained, which confirmed similar behaviour in both. 133 Given the elastic plastic behaviour of the shore-LL unit, the design limit load value was used as a label 134 for the LLs and was associated with a certain shore-LL stiffness value. Following Buitrago et al. 2018a, 135 the limit load of the shore-LL unit was defined as the load corresponding to a stiffness equal to the $57 \%$ 136 of the initial elastic stiffness, while the maximum load was associated with the ultimate load of the shore 137 to make full use of its resistance. A shore without a LL has a linear elastic behavior until failure by 
138 buckling or yielding. A shore with an LL must show the same behavior up to the limit load. However, 139 after the limit load has been reached, and instead of a suddenly breaking and going out of service, the 140 behavior of a shore with an LL becomes perfectly plastic with the formation of three hinges (Buitrago et 141 al. 2020) and keeps the load at its limit load, thus avoiding overloads. This plastic behavior is limited 142 below the available maximum plastic displacement for safety reasons and to prevent excessive slab 143 cracking. When the plastic behavior is initiated, the unloading behavior and reusability conditions of 144 LLs can be found in Buitrago et al. (2018a).

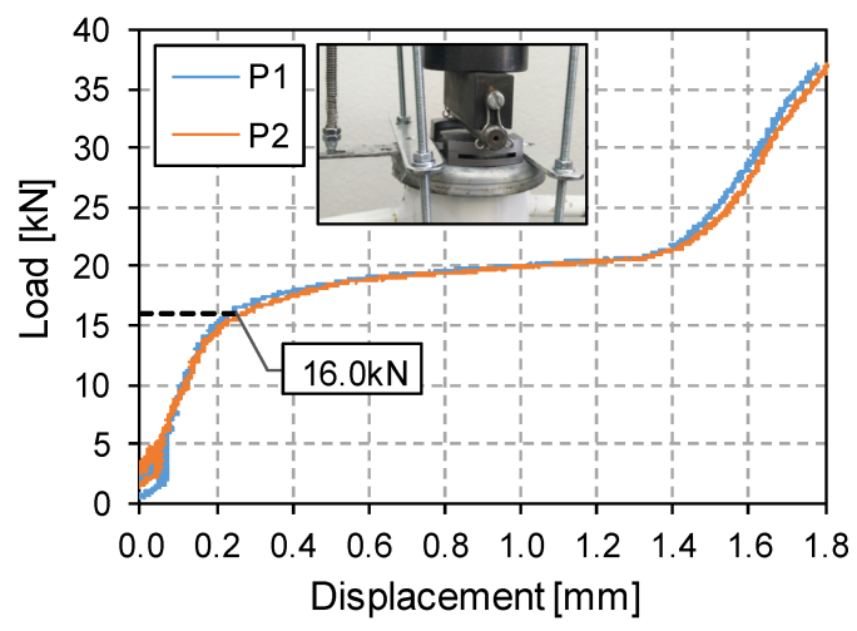

Fig. 3. Preliminary tests on isolated LLs.

\section{$147 \quad$ 3.3. Monitoring and location of LLs}

148 During the test, loads on shores, vertical slab displacement at different points, and internal concrete 149 temperature (slab and specimens) were continuously recorded. Unloaded shores were used subject to the 150 same temperatures as those used for the shoring system to avoid the influence of ambient temperature 151 variations on the recorded shore loads (Alvarado et al. 2009).

152 The devices used to monitor the building were: a) 3 strain gauges on each shore separated by $120^{\circ}$ intervals (a total of 120), b) 14 LVDTs to register vertical slab displacement during the tests, and c) 6

154 thermocouples to follow the concrete mechanical properties gaining with time during curing. Twelve 155 sample readings were taken every minute during the different construction operations, and 0.2 samples 156 per minute in the rest of the tests. 
Fig. 4a shows the shore arrangement and the points at which vertical slab displacement was recorded 158 (identified by the letter "C"). The shore labelling system was as follows: i) prop number, ii) the letter "I" 159 for those with known loads monitored during the tests, and iii) the letter "L" for those fitted with LLs, 160 which were placed on the main joists and formed the shore lines that remained after the clearing or 161 partial striking operations (see Sections 3.1 and 3.4 for further information). Fig. 4b and Fig. 4c show 162 the monitored shores with protection in the zones with strain gauges, plus thus used as reference for 163 temperature control. To control the influence of temperature on the slab/shore load distribution, a 164 number of thermocouples were embedded in the slab at different depths (see Fig. 4d) to measure the 165 temperature gradient. Others were installed in cylindrical specimens placed next to the building (see Fig. $1664 d)$ to analyze temperature differences and specimen and slab concrete curing times. Fig. 4e shows the 167 data acquisition system, whereas Fig. 4f-g show shores without and with LL.
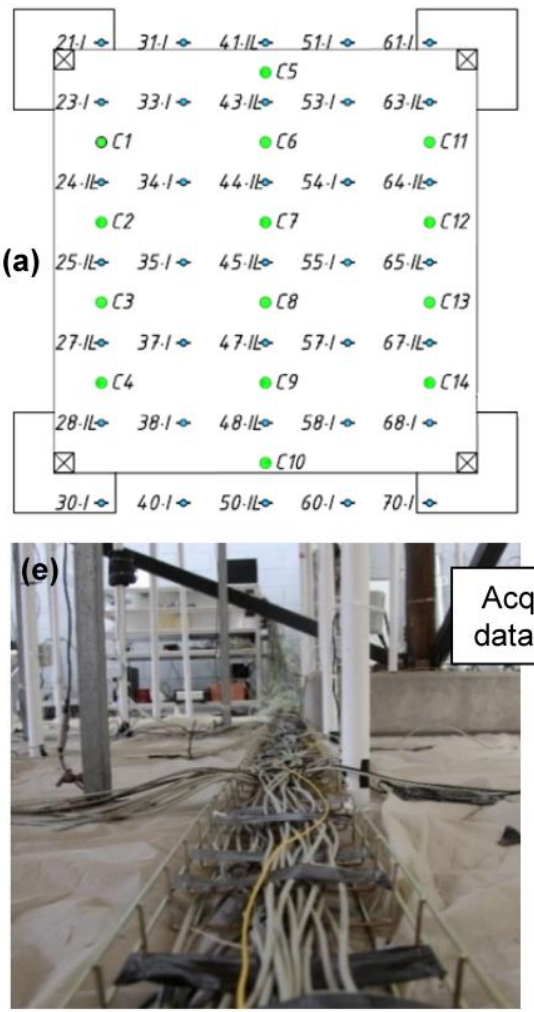

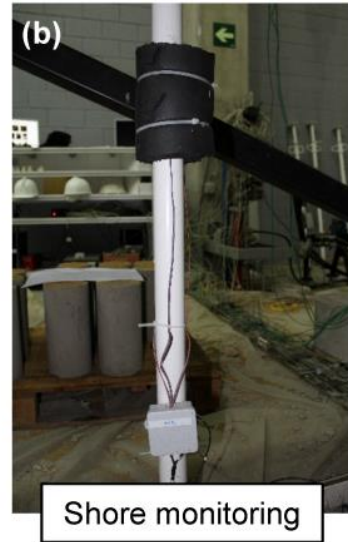

Shore monitoring
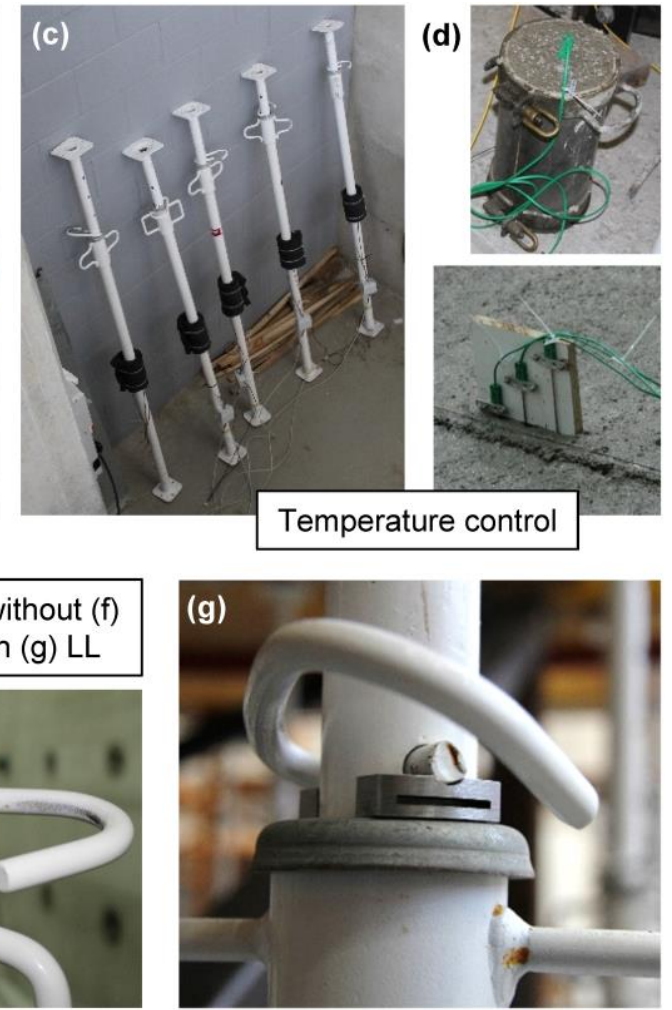

Fig. 4. Distribution of sensors and LLs: (a) location of shores and LVDTs, (b) shore monitoring, (c) reference shores to monitor the temperature influence, $(d)$ thermocouples in specimens and slab, $(e)$ data acquisition 


\subsection{Construction stages}

173 At the present time different processes can be used for shoring successively shored floors (Adam et al. 174 2017), the most usual being as follows: Shoring/Striking (SS), Shoring/Reshoring/Striking (SRS) or 175 Shoring/Clearing (partial striking)/Striking (SCS). SCS was selected for the present study since it 176 reproduces the greater loads on shores than the other systems (Buitrago et al. 2018c). A construction 177 process with clearing or partial striking (SCS), where usually 50\% of shores are removed some days 178 after pouring the concrete over the slab, is the most unfavorable situation for the remaining shores and it 179 is the situation where load limiters play a more important role compared with the other construction 180 processes (SS or SRS) where shores are less loaded (Adam et al. 2017). The system used was as follows: 181 clearing of $50 \%$, removing half the joists a few days after pouring (SJ and their shores - see details in 182 Fig. 2; AJ were also removed) and the formwork boards, in the following stages:

183 1. Day 0: slab casting (see Fig.5a-b) and production of 28 cylindrical specimens to follow the 184 evolution of the concrete mechanical properties. In this stage, the actual density of the reinforced 185 concrete $\left(22.5 \mathrm{kN} / \mathrm{m}^{3}\right)$ was estimated by the shore loads.

186 2. Day 2: Clearing or partial striking, as shown in Fig.5c.

187 3. Day 5: Sand load placed on slab (see Fig. 5d) to reproduce the hypothetical pouring of the second 188 floor. To reach the required loading (see stage 4 for further details) a layer of sand and water pools 189 were used. Sand density was $13.6 \mathrm{kN} / \mathrm{m}^{3}$ in the $17 \mathrm{~cm}$ thick layer; the final load was $2.3 \mathrm{kN} / \mathrm{m}^{2}$.

190 4. Day 7: Pools filled with water, as shown in Fig.5e, to a depth of $50 \mathrm{~cm}$ in $10 \mathrm{~cm}$ stages. An 191 additional load of $5.0 \mathrm{kN} / \mathrm{m}^{2}$ was reached, with a total slab loading of $7.3 \mathrm{kN} / \mathrm{m}^{2}$, to reproduce the 192 hypothetical casting of the second slab with a self-weight equal to that of the first slab $\left(4.5 \mathrm{kN} / \mathrm{m}^{2}\right)$, 193 plus a construction live load of $1.4 \mathrm{kN} / \mathrm{m}^{2}$ on each floor.

194 5. Days 11-12: Water unload/load/unload cycle to check the re-use capability of the load limiters under actual working conditions. Water unloaded down to $15 \mathrm{~cm}$. 
6. Day 13: Striking (Fig. 5f) keeping water load at $15 \mathrm{~cm}$, which together with sand load gave a total value of $3.8 \mathrm{kN} / \mathrm{m}^{2}$, to simulate the hypothetical load of a cleared shoring system on floor 2 .
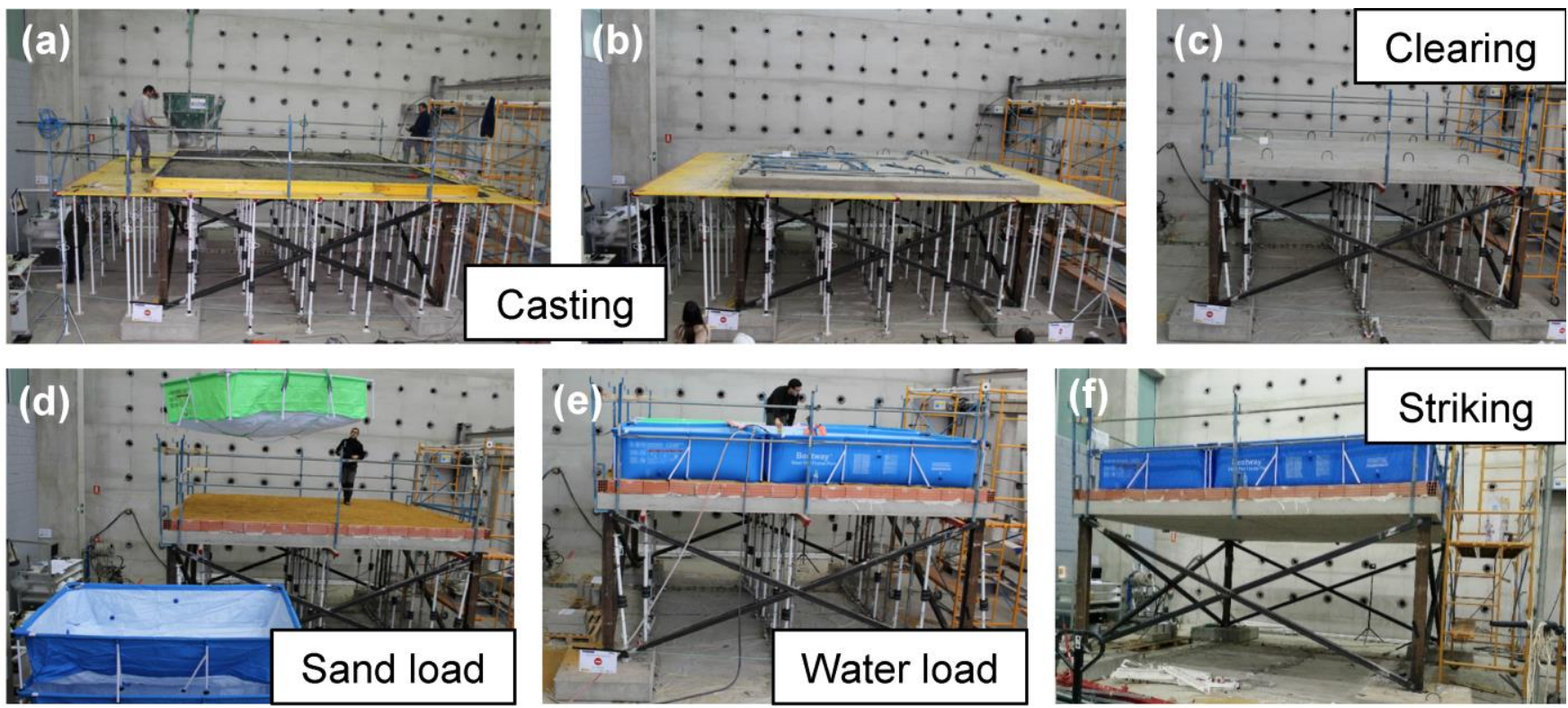

Fig. 5. Summary of the construction stages: $(a)$ and $(b)$ casting, $(c)$ clearing, $(d)$ sand load, $(f)$ water load/unload,

and $(g)$ striking.

201 The mechanical properties of the concrete were measured at different ages: i) elastic modulus (3

202 cylinders, $30 \mathrm{~cm}$ height and $15 \mathrm{~cm}$ diameter, following EN 12390-13); ii) compressive strength (4 203 cylinders, $30 \mathrm{~cm}$ height and $15 \mathrm{~cm}$ diameter, following EN 12390-3); iii) tensile strength (3 Brazilian 204 cylinder tests, 30cm height and 15cm diameter, following EN 12390-6). Table 1 shows the mean values 205 obtained.

Table 1. Evolution of concrete mechanical properties.

\begin{tabular}{llll}
\hline Construction stage & $\begin{array}{l}\text { Elastic } \\
\text { Modulus } \\
{[\mathbf{M P a}]}\end{array}$ & $\begin{array}{l}\text { Compressive } \\
\text { strength } \\
{[\mathbf{M P a}]}\end{array}$ & $\begin{array}{l}\text { Tensile } \\
\text { Strength } \\
{[\mathbf{M P a}]}\end{array}$ \\
\hline Clearing - Day 3 & 27777 & 19.8 & 2.0 \\
Water Load - Day 7 & 30005 & 26.1 & 2.3 \\
Striking (Day 13) & 31707 & 30.0 & 2.3 \\
Day 28 & 34215 & 33.4 & 2.5 \\
\hline
\end{tabular}




\section{4. Test results}

212 The results in terms of loads on shores and vertical LVDT displacements were obtained throughout the

213 tests. As an example, Fig. 6 shows the evolution of the most heavily loaded shore (43-IL) during the test.

214 The maximum load recorded was $17.7 \mathrm{kN}$ (see Section 5 for further information) and the loads varied

215 throughout the different operations (casting, clearing, sand and water loading, and striking). The shores 216 fitted with LLs reached their maximum load and, as planned in their design, when loading/unloading

217 recovered the load applied and went on to reach a similar level to the situation prior to unloading, thus

218 confirming their ability to deal with actual on-site conditions. Table 2 gives a summary of the loads on 219 the props on the main joists in each building operation, with those on which the loads reached 16.0kN 220 shown in bold.

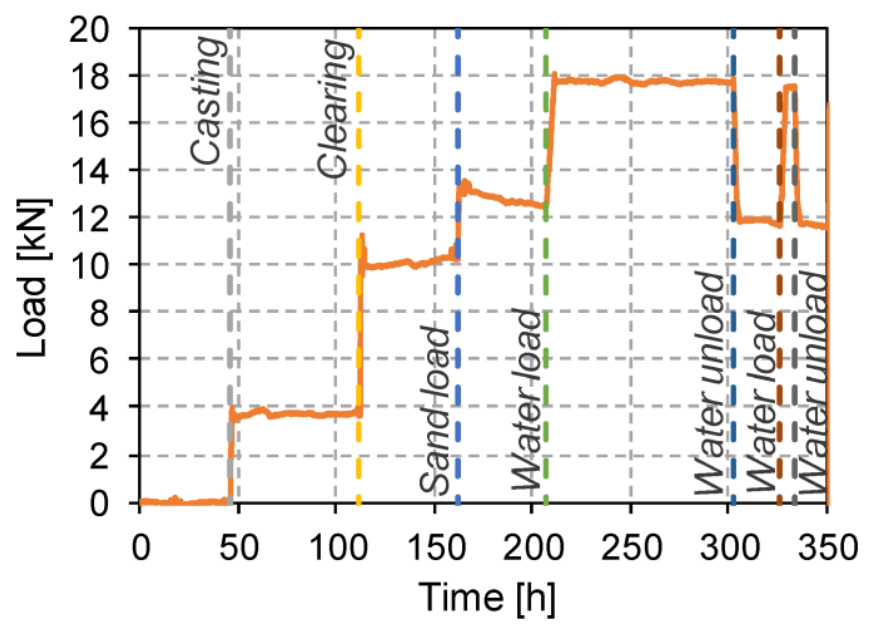

Fig. 6. Load on shore 43.IL during the test. 
Table 2. Loads of shores of the main joists during test. Units in $\mathrm{kN}$.

\begin{tabular}{|c|c|c|c|c|c|c|c|}
\hline \multirow{2}{*}{ Shore } & \multicolumn{7}{|c|}{ Construction stage } \\
\hline & Casting & Clearing & Sand load & Water load & Water unload & Water load & Water unload \\
\hline $23 \cdot I$ & 1.8 & 2.9 & 4.0 & 6.0 & 4.5 & 6.0 & 4.6 \\
\hline $24 \cdot \mathrm{IL}$ & 5.4 & 9.6 & 11.5 & 15.7 & 12.0 & 15.2 & 11.9 \\
\hline $25 \cdot \mathrm{IL}$ & 3.8 & 6.5 & 8.8 & 12.5 & 8.1 & 12.1 & 7.9 \\
\hline $27 \cdot \mathrm{IL}$ & 4.5 & 7.4 & 8.7 & 11.7 & 7.6 & 10.8 & 7.4 \\
\hline $28 \cdot \mathrm{IL}$ & 3.2 & 7.6 & 9.6 & 14.1 & 10.9 & 13.8 & 10.7 \\
\hline $30 \cdot \mathrm{IL}$ & 0.1 & 0.1 & 0.5 & 1.1 & 1.0 & 1.1 & 1.0 \\
\hline $43 \cdot I L$ & 3.7 & 9.9 & 12.9 & 17.7 & 11.9 & 17.2 & 11.7 \\
\hline $44 \cdot \mathrm{IL}$ & 4.8 & 6.2 & 8.5 & 12.4 & 6.2 & 10.7 & 5.8 \\
\hline $45 \cdot \mathrm{IL}$ & 5.6 & 8.5 & 10.1 & 14.6 & 8.4 & 12.9 & 7.9 \\
\hline $47 \cdot \mathrm{IL}$ & 5.0 & 10.4 & 12.1 & 16.1 & 8.4 & 14.4 & 7.8 \\
\hline $48 \cdot \mathrm{IL}$ & 4.5 & 10.1 & 12.2 & 17.0 & 11.8 & 16.0 & 11.5 \\
\hline $50 \cdot \mathrm{IL}$ & 0.6 & 0.7 & 1.4 & 3.2 & 2.2 & 3.0 & 2.3 \\
\hline $63 \cdot \mathrm{IL}$ & 2.7 & 4.0 & 4.7 & 6.6 & 4.9 & 5.7 & 4.9 \\
\hline $64 \cdot \mathrm{IL}$ & 4.6 & 8.9 & 11.3 & 15.8 & 11.4 & 14.9 & 11.4 \\
\hline $65 \cdot \mathrm{IL}$ & 3.6 & 8.7 & 11.3 & 15.8 & 10.9 & 15.3 & 10.9 \\
\hline $67 \cdot \mathrm{IL}$ & 3.8 & 7.0 & 8.6 & 13.8 & 9.4 & 12.5 & 9.2 \\
\hline $68 \cdot I$ & 2.4 & 5.7 & 6.6 & 9.2 & 6.6 & 8.7 & 6.5 \\
\hline $70 \cdot I$ & 0.1 & 0.2 & 0.3 & 0.6 & 0.5 & 0.8 & 0.5 \\
\hline
\end{tabular}

The slab deflection was recorded by the LVDTs on telescopic metal tubes joined to the main joists and resting on the floor. Fig. 7 shows the readings at point C7 (Fig. 4) and how vertical displacement 227 increased during the different operations. When loading/unloading after activating the plastic phase in some LLs, deflection again rose to a similar level to that before unloading, showing that the LLs could be re-used in actual on-site conditions (see Section 5.4 for further information).

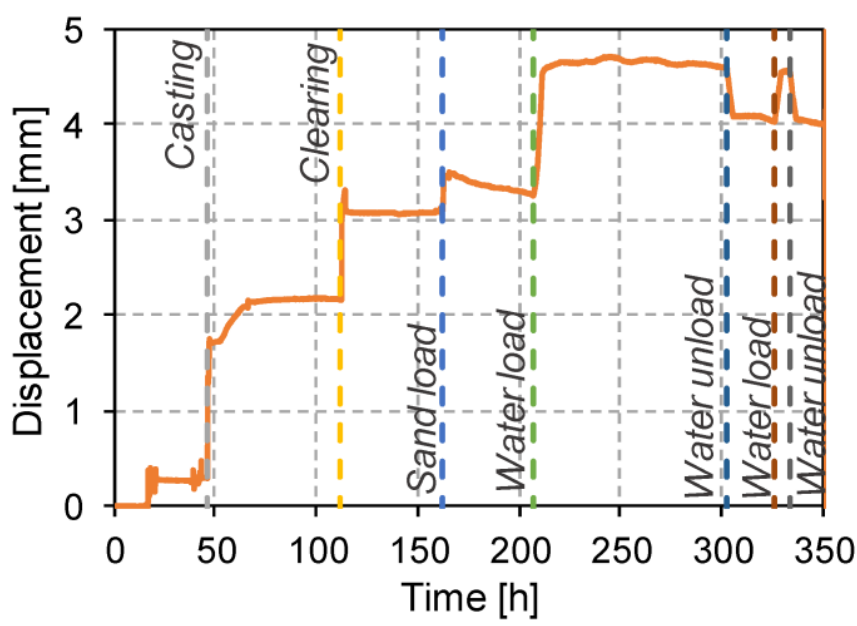




\section{5. Discussion and recommendations}

235 This section first contains a discussion of the test results, including: a) load transmission between slab

236 and shores, b) shore force-displacement curves, and c) results without LLs, and ends with a series of 237 recommendations.

\section{5.1. Load transmission between slab and shores}

239 The building sequence is normally designed by evaluating the slab/shore load transmissions, which is 240 commonly done by estimating the part of the applied load (in $\mathrm{kN} / \mathrm{m}^{2}$ ) borne by the slabs and shores. The 241 applied loads on slabs $\left(\mathrm{Q}_{\text {slab}}\right)$ and shores $\left(\mathrm{S}_{\text {shores }}\right)$ per surface unit are widely used parameters. The mean 242 ( $\left.\mathrm{S}_{\text {mean }}\right)$ and maximum loads $\left(\mathrm{S}_{\max }\right)$ on shores $(\mathrm{in} \mathrm{kN})$ are also estimated to help select the type of shore to 243 be used. Table 3 shows the recorded transmitted slab/shore loads. The maximum load does not exceed $24417.7 \mathrm{kN}$ when LLs are used. It should be remembered that the expected maximum load without LLs was $24523.0 \mathrm{kN}$. It can also be seen that the slab/shore load distribution and maximum and mean loads on shores 246 are similar after the unloading/loading water cycle. These experimental results were also used to 247 calibrate the numerical model described in Section 5.3.

248 Table 3. Load transmission between slab and shores during the test.

\begin{tabular}{lllll}
\hline $\begin{array}{l}\text { Construction } \\
\text { stage }\end{array}$ & $\begin{array}{l}\mathbf{Q}_{\text {slab }} \\
\left(\mathbf{k N} / \mathbf{m}^{2}\right)\end{array}$ & $\begin{array}{l}\mathbf{S}_{\text {shores }} \\
\left(\mathbf{k N} / \mathbf{m}^{2}\right)\end{array}$ & $\begin{array}{l}\mathbf{S}_{\max } \\
(\mathbf{k N})\end{array}$ & $\begin{array}{l}\mathbf{S}_{\text {mean }} \\
(\mathbf{k N})\end{array}$ \\
\hline Casting & 0.1 & 4.4 & 6.2 & 3.5 \\
Clearing & 0.3 & 4.2 & 10.6 & 6.4 \\
Sand load & 1.5 & 5.4 & 13.2 & 8.2 \\
Water load & 4.3 & 7.4 & 17.7 & 11.4 \\
Water unload & 3.3 & 5.0 & 11.9 & 7.6 \\
Water load & 4.7 & 7.1 & 17.5 & 10.8 \\
Water unload & 3.4 & 4.9 & 11.9 & 7.5 \\
Striking & 8.3 & 0.0 & 0.0 & 0.0 \\
\hline
\end{tabular}

$250 \quad$ 5.2. Force-displacement curves

251 Loads on shores and vertical displacement at points close to shores were also recorded during the test to 252 estimate the downward movement of the slab around the shores (mean LVDT readings close to the 253 shores) and draw the shore's force-displacement curve. The slope of the curve corresponds to the shore- 
254 LL unit stiffness and demonstrates the LL behaviour and the moment they come into action. Table 4 255 gives the calculated initial shore stiffness.

256 Table 4. Initial stiffness of different shores.

\begin{tabular}{ll}
\hline Shore & Stiffness $[\mathbf{k N} / \mathbf{m m}]$ \\
\hline P24·IL & 7.07 \\
P25·IL & 5.21 \\
P27·IL & 4.03 \\
P43·IL & 8.00 \\
P44·IL & 4.71 \\
P45·IL & 5.02 \\
P47·IL & 6.14 \\
P48·IL & 7.94 \\
P64·IL & 7.13 \\
P65·IL & 6.88 \\
P67·IL & 6.45 \\
\hline Average & $\mathbf{6 . 2 4}$ \\
\hline
\end{tabular}

258 For example, Fig. 8a shows the force-displacement curve of the most heavily loaded shore (43·IL), close 259 to the centre of the bay, in which maximum load was recorded because it was also the stiffest shore. It 260 can be seen that the shore-LL unit has linear behavior at low loads, but not at higher loads, when 261 stiffness (k) progressively falls, showing the clearly (non-linear) plastic behavior of the LL on this shore. 262 As foreseen (see Section 3.2), $\mathrm{k}$ is less than $57 \%$ of the original stiffness when the load is above $16.0 \mathrm{kN}$. 263 This reduced stiffness means that the shore stops absorbing a higher load with reference to the 264 hypothetical case without LLs and re-distributes the excess to the neighboring shores via the slab. Fig. 265 8b shows the condition of the LL on this shore under the maximum load. It can be seen in both graph 266 and photo that the LL deformed as foreseen, confirming its appropriate behaviour under working 267 conditions. 

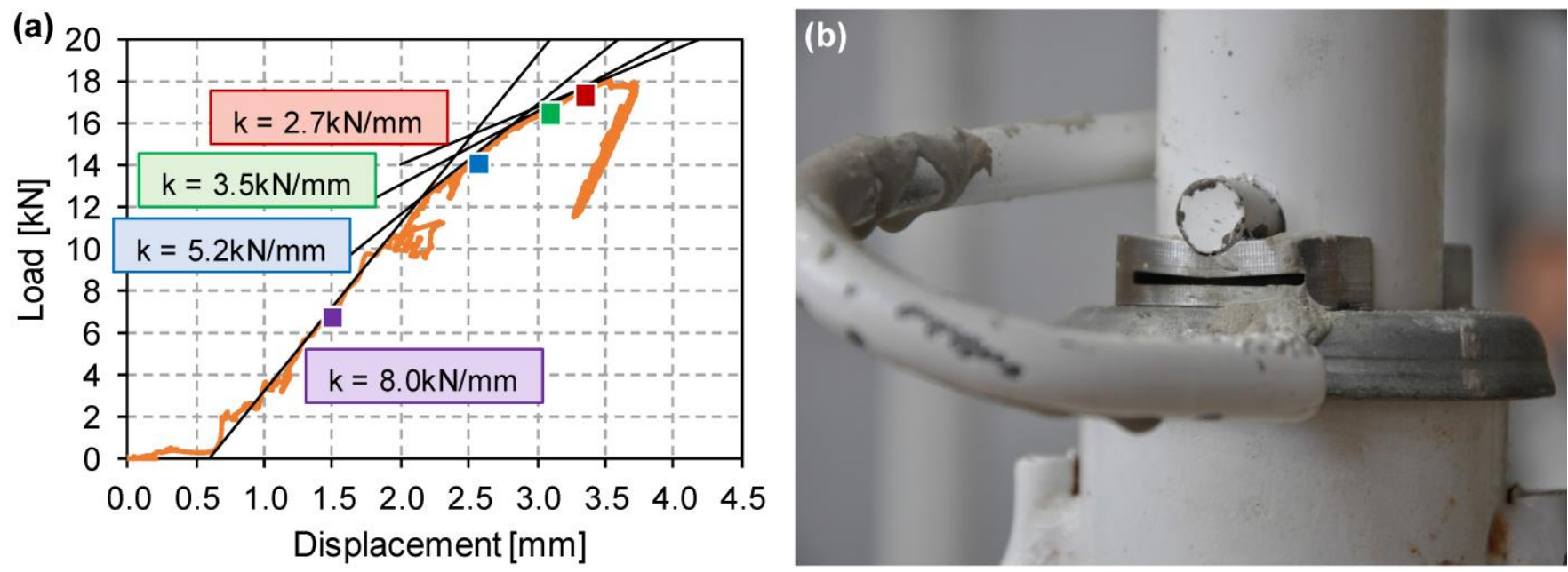

Fig. 8. (a) Force-displacement curve (shore 43.IL); (b) state of the LL at the moment of the maximum load of

$17.7 \mathrm{kN}$

\section{5.3. Assessment of temporary shoring structure behaviour without LLs}

272 After confirming the viability of LLs in actual building operations, this section speculates on what 273 would have happened in the test if LLs had not been fitted to the shores by means of FEM linear elastic 274 analysis of the construction process involved in the experiment using ANSYS software (v15 2014). 275 Columns and joists were considered as beam elements (BEAM188) and shores were considered as truss 276 elements (LINK180) working under compressive forces only. The SHELL181 element was considered 277 for the slab and formwork boards. Besides the construction process, the geometric and mechanical 278 characteristics of the elements in the building were also considered by evolutionary calculation in 279 different steps. The BIRTH and DEATH options can activate and deactivate elements during the 280 different steps to reproduce the construction process. Command MPCHNG was used to update the 281 mechanical properties of the material (elastic modulus). The hypotheses adopted to carry out the FE 282 model were as follows:

283 - Shores without LLs were considered to have linear elastic behavior with their actual stiffness and 284 simply supported at each end. Those with LLs were considered with elastic-plastic behavior, 
adopting the force-displacement curve of the shore-LL unit monitored during the test (see example in Section 5.2).

- Formwork boards, columns, joists and the slab were considered as elements with linear elastic behavior. The boards were of wood, while columns and joists were steel, all of which were faithfully represented in the FE model. The concrete slab was considered to have varying stiffness with time (see Table 1) according to the measured variation of the elastic modulus.

- Columns were totally restrained (fixed displacements and rotations) at the foundations, whereas shores were only simply supported (fixed displacements in the lower nodes).

293 Fig. 9 shows a series of images of the FE model during different construction stages: casting, clearing 294 and the application of a load on the slab. Fig. 10 compares the experimental and FE model results of the 295 load evolution of the most heavily loaded shore (43.IL). The model results can be seen to be almost 296 identical with the experimental results, showing a good fit.

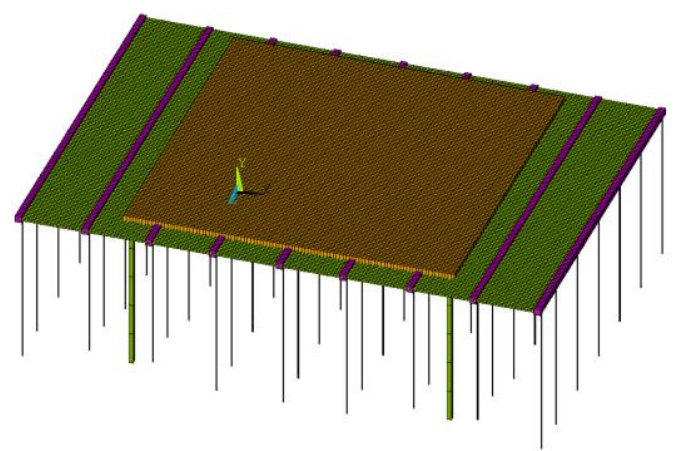

Casting
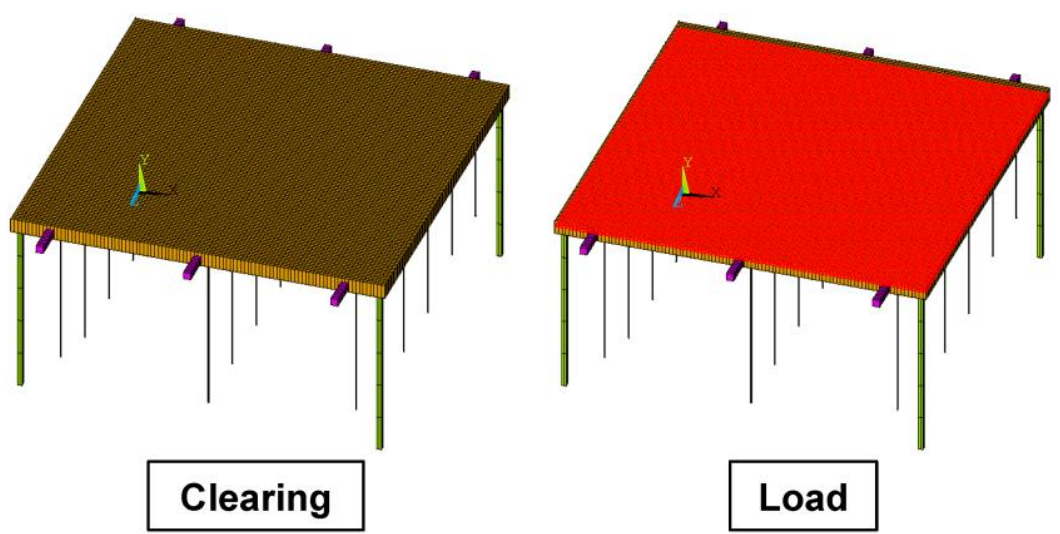

Fig. 9. FEM of the test during different construction stages. 


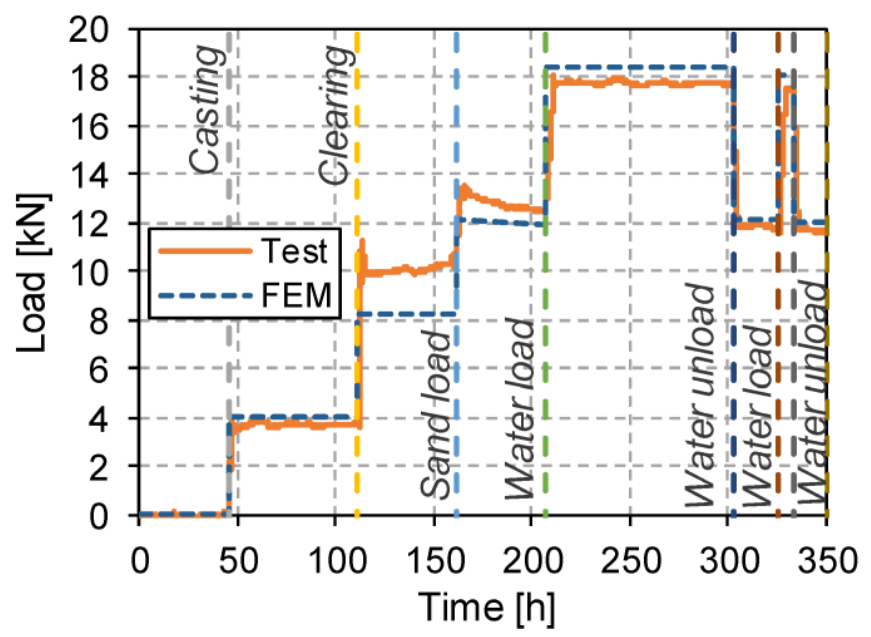

Fig. 10. Comparison of load evolution during test according to the experimental data and FEM results.

301 The FE model thus shows a good fit with the experimental results and gives an idea of how the building 302 would have behaved if LLs had not been installed on the shores. Table 5 gives the mean and maximum 303 loads on shores with (SFEM-LL) and without (SFEM) LLs. It can be seen that both mean and maximum 304 loads on the shoring system are always lower when LLs are fitted, when maximum load remained at $30518.4 \mathrm{kN}$. On the other hand, when they are not used, the maximum load on the shoring system would 306 have reached $22.1 \mathrm{kN}$, significantly higher than the maximum actually received, so that the LLs reduced 307 the maximum load by $17 \%$.

308 Table 5. Load on shoring system and load on most heavily loaded shore.

\begin{tabular}{lllcc}
\hline & \multicolumn{2}{c}{$\mathbf{S}_{\text {shores }}\left[\mathbf{k N} / \mathbf{m}^{\mathbf{2}}\right]$} & \multicolumn{2}{c}{$\mathbf{S}_{\max }[\mathbf{k N}]$} \\
\cline { 2 - 5 } Construction stage & $\mathrm{S}_{\text {FEM-LL }}$ & $\mathrm{S}_{\text {FEM }}$ & $\mathrm{S}_{\text {FEM-LL }}$ & $\mathrm{S}_{\text {FEM }}$ \\
\hline Casting & 4.4 & 4.4 & 5.1 & 5.1 \\
Clearing & 3.1 & 3.2 & 8.4 & 8.7 \\
Sand load & 4.6 & 4.7 & 12.4 & 13.0 \\
Water load & 7.4 & 8.0 & 18.4 & 22.1 \\
Water unload & 5.0 & 5.6 & 12.1 & 15.5 \\
Water load & 7.2 & 7.9 & 18.0 & 21.8 \\
Water unload & 4.9 & 5.6 & 12.0 & 15.4 \\
\hline
\end{tabular}

310 The evolution of the loads on shores is another indicator of the effect of the LLs during the test. Fig. 11 311 compares the evolution of the load on the most heavily loaded shore obtained by the FE model (43. IL) 312 with (FEM-LL) and without (FEM) LLs. In both situations the load can be seen to be identical until the 313 LL design load is exceeded under the water loading. 


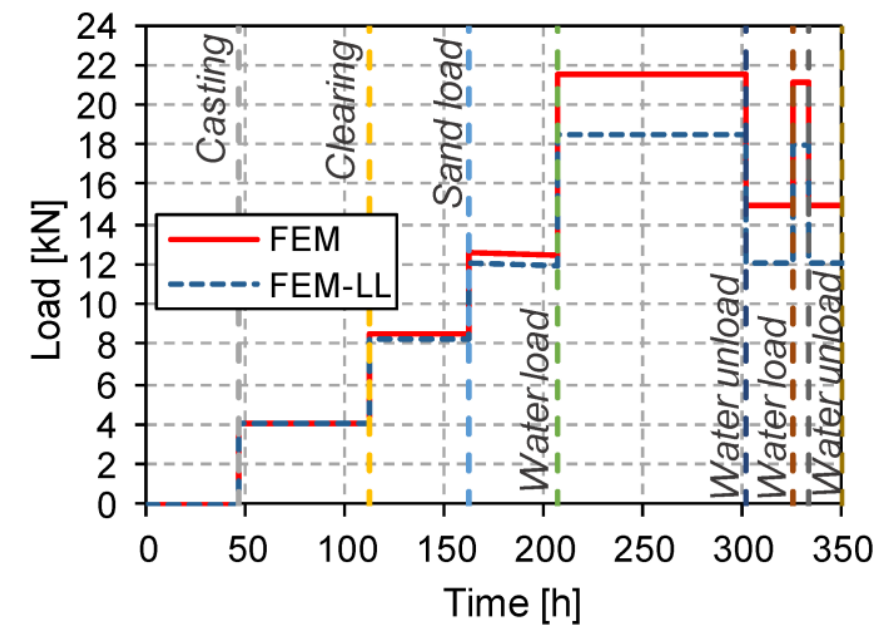

Time [h]

Fig. 11. Load on most heavily loaded shore without (FEM) and with LLs (FEM-LL).

\section{5.4. Recommendations}

317 This section offers some practical recommendations for the use of LLs on shores during building work, 318 which is expected to be useful to engineers and architects, besides construction companies and 319 formwork producers in the construction of RC building structures.

320 Although to keep costs low not all the shores were fitted with LLs during the tests, it is recommended to 321 install them on all shores during an actual construction project because, as occurred in the test and in 322 other cases (Alvarado et al. 2009) it is always difficult to identify the most heavily loaded shores. This 323 does not necessarily mean higher costs as the LLs have clearly proved that they can be re-used (Buitrago 324 et al. 2018a). It is also advisable to replace the LLs after wearing out half the slot of the maximum 325 permitted plastic displacement (Buitrago et al. 2018a) because: a) the accumulated damage is 326 considerable and b) the available permitted plastic displacement is reduced. In addition, even though it 327 would be possible to design better shoring systems, it is not recommended to install LLs only on certain 328 shores or use different LL designs on the same floor, as this would increase the risk of mistakes on 329 installing the shoring system.

330 As shown by the tests, fitting LLs to shores can reduce the maximum load on a shoring system by as 331 much as $17 \%$, or more than $30 \%$ in previous numerical studies (Buitrago et al. 2015). However, this 
332 reduction has a limit that depends on the individual case. When the LLs start to deform they limit the

333 load received by the shore and re-distribute the excess to neighboring shores via the slab. This means

334 that the slab and shores around the most heavily loaded shore receive a higher load and cause further

335 vertical slab displacement. It is recommended not to damage slabs and avoid concrete cracking under

336 construction to ensure their durability and avoid significantly increased short- and long-term deflections.

337 Reducing maximum load also involves choosing lighter and cheaper shores for the construction of the

338 entire building. This type of lighter and more economic shores will reduce shoring costs and make the

339 builder's work easier, as has been shown in previous studies (Buitrago et al. 2015).

340 6. Conclusions

341 This paper has described the design, analysis and testing of load limiters (LLs) on shores in a full-scale

$3423 \mathrm{D}$ test carried out in realistic working conditions. From the results obtained the following conclusions 343 can be drawn:

344 - Building safety is increased as the LLs keep the loads on shores below the admissible load.

345 - Using LLs means a more efficient temporary shoring structure since they take full advantage of the 346 shore strength capacity, i.e. more shores operate under similar loads and lower maximum loads 347 using the full capacity of the shoring system and avoiding using systems with higher design loads.

348 - Adopting LLs means that lighter and less resistant shores can be used, leading to savings in the 349 shoring system and easing the builders' work when installing lighter shores.

350 - The LLs were shown to be re-usable under actual working conditions due to the unload/load/unload 351 cycle that was performed during test. Their reusability for more cycles, under laboratory conditions, 352 is addressed in a previous study (Buitrago et al. 2018a).

353 - It is recommended to use the same type of LL (same design limit load) for all the shores in a shoring 354 system in order to avoid possible errors in their installation. When selecting them it should be 355 remembered that reducing their maximum load is limited to a maximum value to avoid slab 
cracking during construction so as not to prejudice short- and long-term behavior of the structure and its durability. This restriction will vary from case to case, although situations have been evaluated in which LLs have reduced the maximum load on shores by more than $30 \%$ without causing cracks in the slabs.

360 The results obtained have revealed a series of important advantages to the industry as a whole in that 361 they improve the construction process as regards economy, structural safety and efficiency. Although 362 the present study covers the worst situation and most of the situations where load limiters can be applied 363 efficiently, future works might consider different construction processes or parametric analyses carried 364 out with the help of the validated computational model presented in this study.

\section{Data Availability Statement}

366 Some or all data, models, or code that support the findings of this study are available from the 367 corresponding author upon reasonable request.

\section{Acknowledgements}

369 The authors would like to express their gratitude to the Spanish Ministry of Education, Culture and 370 Sport for funding received under the FPU Program [FPU13/02466], to the Generalitat Valenciana 371 [GV/2015/063] and also to the Levantina, Ingeniería y Construcción S.L. and Encofrados J. Alsina S.A. 372 business companies for their invaluable cooperation.

\section{References}

Adam, J. M., Buitrago, M., Moragues, J. J., and Calderón, P. A. (2017). "Limitations of Grundy \& Kabaila's simplified method and its repercussion on the safety and serviceability of successively shored building structures." Journal of Performance of Constructed Facilities, 31(5), 1-10.

Adam, J. M., Parisi, F., Sagaseta, J., and Lu, X. (2018). "Research and practice on progressive collapse and robustness of building structures in the 21st century." Engineering Structures, 173, 122-149.

Alvarado, Y. A., Buitrago, M., Gasch, I., Domínguez, M. N., and Cipagauta, M. A. (2017). "Short- and long-term deflections of RC building structures influenced by construction processes." Structural engineering and mechanics, 64(2), 173-181.

383 Alvarado, Y. A., Calderón, P. A., Adam, J. M., Payá-Zaforteza, I. J., Pellicer, T. M., Pallarés, F. J., and 
Moragues, J. J. (2009). "An experimental study into the evolution of loads on shores and slabs during construction of multistory buildings using partial striking." Engineering Structures, 31(9), 2132-2140.

ANSYS v15. (2014). “Theory reference. ANSYS Inc."

BS 5975. (2011). "Code of practice for temporary works procedures and the permissible stress design of falsework." BSI Standards Publication.

Buitrago, M., Adam, J. M., Alvarado, Y. A., Calderón, P. A., and Gasch, I. (2016a). "Maximum loads on shores during the construction of buildings." Proceedings of the Institution of Civil Engineers Structures and Buildings, Thomas Telford Ltd, 169(7), 538-545.

Buitrago, M., Adam, J. M., Alvarado, Y. A., Moragues, J. J., Gasch, I., and Calderón, P. A. (2016b). "Designing construction processes in buildings by heuristic optimization." Engineering Structures, $111,1-10$.

Buitrago, M., Adam, J. M., Calderón, P. A., and Moragues, J. J. (2018a). "Load limiters on shores: Design and experimental research.” Engineering Structures, 173, 1029-1038.

Buitrago, M., Alvarado, Y. A., Adam, J. M., Calderón, P. A., Gasch, I., and Moragues, J. J. (2015). "Improving construction processes of concrete building structures using load limiters on shores." Engineering Structures, 100, 104-115.

Buitrago, M., Moragues, J. J., Calderón, P. A., and Adam, J. M. (2018b). "Structural failures in cast-inplace RC building structures under construction." Handbook of Materials Failure Analysis with Case Studies from the Construction Industries, Volumen 6, A. S. H. Makhlouf and M. Aliofkhazraei, eds., Butterworth-Heinemann, Elsevier, 560.

Buitrago, M., Sagaseta, J., and Adam, J. M. (2018c). "Effects of sudden failure of shoring elements in concrete building structures under construction." Engineering Structures, 172, 508-522.

Buitrago, M., Sagaseta, J., and Adam, J. M. (2020). "Avoiding failures during building construction using structural fuses as load limiters on temporary shoring structures." Engineering Structures, 204, 109906.

Calderón, P. A., Adam, J. M., Buitrago, M., Alvarado, Y. A., and Moragues, J. J. (2017). "Limitador de carga para puntales telescópicos de obra - Patent number ES2636833.” Spain.

Calderón, P. A., Alvarado, Y. A., and Adam, J. M. (2011). "A new simplified procedure to estimate loads on slabs and shoring during the construction of multistorey buildings." Engineering Structures, 33(5), 1565-1575.

Carper, K. L. (1987). "Structural Failures During Construction.” Journal of Performance of Constructed Facilities, American Society of Civil Engineers, 1(3), 132-144.

El-Tawil, S., Li, H., and Kunnath, S. (2014). "Computational Simulation of Gravity-Induced Progressive Collapse of Steel-Frame Buildings: Current Trends and Future Research Needs." Journal of Structural Engineering, 140(8), 1-12.

Ellingwood, B. (1987). "Design and construction error effects on structural reliability." Journal of Structural Engineering, 113(2), 409-422.

Epaarachchi, D. C., Stewart, M. G., and Rosowsky, D. V. (2002). "Structural Reliability of Multistory Buildings during Construction." Journal of Structural Engineering, American Society of Civil Engineers, 128(2), 205-213. 
Fang, D. P., Zhu, H. Y., Geng, C. D., and Liu, X. La. (2001). "On-site measurement of load distribution in reinforced concrete buildings during construction.” ACI Structural Journal, 98(2), 157-163.

Gasch, I., Alvarado, Y. A., Calderón, P. A., and Ivorra, S. (2015). "Construction loads using a shoringclearing-striking process." Proceedings of the Institution of Civil Engineers - Structures and Buildings, Thomas Telford Ltd, 167(4), 217-229.

Ghali, A., and Gayed, R. B. (2014). "Sustainable Serviceability of Structural Concrete: Control of Deflection and Cracking." Journal of Structural Engineering, 140(7), 1-9.

Hadipriono, F. C. (1985). “Analysis of Events in Recent Structural Failures.” Journal of Structural Engineering, 111(7), 1468-1481.

Hadipriono, F. C., and Wang, H.-K. (1987). "Causes of falsework collapses during construction." Structural Safety, 4(3), 179-195.

Karshenas, S., and Ayoub, H. (1994). "Analysis of Concrete Construction Live Loads on Newly Poured Slabs." Journal of Structural Engineering, American Society of Civil Engineers, 120(5), 15251542.

Liu, X. la, Chen, W. F., and Bowman, M. D. (1985). "Construction Load Analysis for Concrete Structures." Journal of Structural Engineering, American Society of Civil Engineers, 111(5), 1019-1036.

Qian, K., and Li, B. (2013). "Performance of Three-Dimensional Reinforced Concrete Beam-Column Substructures under Loss of a Corner Column Scenario." Journal of Structural Engineering, 139(4), 584-594.

Sasani, M., Kazemi, A., Sagiroglu, S., and Forest, S. (2011). "Progressive Collapse Resistance of an Actual 11-Story Structure Subjected to Severe Initial Damage.” Journal of Structural Engineering, 137(9), 893-902.

Sasani, M., and Sagiroglu, S. (2008). "Progressive Collapse Resistance of Hotel San Diego." Journal of Structural Engineering, 134(3), 478-488.

Schellhammer, J., Delatte, N. J., and Bosela, P. A. (2013). "Another Look at the Collapse of Skyline Plaza at Bailey's Crossroads, Virginia." Journal of Performance of Constructed Facilities, American Society of Civil Engineers, 27(3), 354-361.

Zhang, H., Reynolds, J., Rasmussen, K. J. R., and Ellingwood, B. R. (2016). "Reliability-Based Load Requirements for Formwork Shores during Concrete Placement." Journal of Structural Engineering, American Society of Civil Engineers, 142(1), 1-9. 